\title{
Reducing the impact of coaching on selection into medicine
}

Barbara Griffin BPsych(Hons), PhD

Wendy CY Hu MBBS(Hons), PhD, FRACGP'

1 Macquarie University Sydney, NSW.

2 Western Sydney University Sydney, NSW.

barbara.griffin@ mq.edu.au students had slightly higher scores on the non-verbal test of logical reasoning. ${ }^{3}$ Similar results were obtained in a New Zealand study, which involved students who had been coached by the MedEntry company. ${ }^{4}$ Even though these students believed that their UMAT performance would be improved, this belief was misplaced as their UMAT results were no better than those of uncoached students.

\section{"the time and money spent on commercial coaching appears to be misdirected"} suggests that UMAT scores achieved after coaching may not represent true ability to do medicine, or that students who rely on coaching cope less well in academic environments where coaching is not appropriate.

A study of Year 12 high school students in New South Wales and Victoria showed that coaching had no impact on the UMAT sections that assess problem solving or understanding people, but coached

Subsequently, only $35.5 \%$ of those invited to interview had engaged in commercial UMAT coaching, a significant decrease from the $51.4 \%$ of interviewees who were coached in $2008^{1}\left(\chi^{2}=7.43 ; P=0.003\right)$.

There was no statistical difference between coached $(n=122)$ and uncoached $(n=222)$ interviewees on any of the three UMAT scores $(P=0.891,0.885$ and 0.945 for UMAT Sections 1, 2 and 3, respectively) or the Multiple Mini Interview scores $(P=0.352)$. Thus, the coached group were no more likely to gain entrance to the medical program. However, the coached group had higher academic university entrance ranking scores (ATAR) than their uncoached peers (mean ATAR = 98.76 v 98.01; $t=2.99 ; P=0.003)$. Applicants who are likely to be shortlisted for interviews and yet feel the need for UMAT coaching may be less confident in their own ability or more susceptible to industry advertising - but the time and money spent on commercial coaching appears to be misdirected.

\section{Competing interests: No relevant disclosures.}

Provenance: Not commissioned; not externally peer reviewed.

(c) 2015 AMPCo Pty Ltd. Produced with Elsevier B.V. All rights reserved.

References are available online at www.mja.com.au. 
1 Griffin B, Harding DW, Wilson IG, Yeomans ND. Does practice make perfect? The effect of coaching and retesting on selection tests used for admission to an Australian medical school. Med J Aust 2008; 189: 270-273. https://www.mja.com. au/journal/2008/189/5/does-practice-make-perfect-effectcoaching-and-retesting-selection-tests-used

2 Griffin B, Yeomans ND, Wilson IG. Students coached for an admission test perform less well throughout a medical course. Internal Med J 2013; 43: 927-932.
3 Griffin B, Carless S, Wilson I. The effect of commercial coaching on selection test performance. Med Teach 2013; 35: 295-300.

4 Wilkinson TM, Wilkinson TJ. Preparation courses for a medical admissions test: effectiveness contrasts with opinion. Med Educ 2013; 47: 417-424. 